\title{
O PERFIL DA PESQUISA ACADÊMICA SOBRE EDUCAÇÃO A DISTÂNCIA NO BRASIL E NO MUNDO ${ }^{1}$
}

\author{
Thalita de Oliveira Pelegrini ${ }^{2}$ \\ Sheila Serafim da Silva ${ }^{3}$ \\ Maxwel de Azevedo-Ferreira ${ }^{4}$ \\ Murilo Alvarenga Oliveira ${ }^{5}$
}

http://dx.doi.org/10.1590/1413-2311.156.58270

\begin{abstract}
RESUMO
A Educação a Distância $(\mathrm{EaD})$ ganhou destaque com o avanço das tecnologias, fazendo com que muitos pesquisadores se voltassem para o tema. A partir disso, justifica-se a importância de compreender a dinâmica do campo de estudo sobre EaD para o avanço da ciência e identificação de lacunas e vieses na produção do conhecimento. Este estudo teve como objetivo analisar o perfil internacional da pesquisa acadêmica sobre $\mathrm{EaD}$ e, mais especificamente, a participação brasileira nessas pesquisas. Foram utilizadas técnicas bibliométricas, visto que os indicadores da produção científica retratam o desenvolvimento de uma área do conhecimento. $\mathrm{O}$ estudo combinou os termos "Distance Education", "E-learning" e "Elearning" na base de dados Web of Science (WoS). Realizaram-se os seguintes procedimentos: (1) definição dos termos mais adequados para a extração de dados de artigos relativos ao interesse da pesquisa; (2) busca e extração nas bases de dados; (3) limpeza e organização dos dados e (4) análises bibliométricas e interpretação. Os resultados apontaram que o tema é de interesse global e apresenta interação entre alguns países, com destaque para os Estados Unidos, como o país que mais publicou sobre o tema. A EaD está sendo pesquisada por um número considerável de autores que, juntos, somam 17.789, indicando que o tema está caminhando para maturidade no que diz respeito à análise internacional. Os resultados apontaram, ainda, que as publicações sobre EaD no Brasil possuem cooperação internacional, podendo ser um indicativo de que o Brasil está publicando com os principais países que pesquisam sobre o tema. A partir dessas evidências, a pesquisa pôde contribuir com o mapa do perfil da pesquisa acadêmica sobre EaD no Brasil e no mundo que pode ser útil aos pesquisadores da área.
\end{abstract}

Palavras-chave: Educação a Distância; Perfil de Pesquisa; Bibliometria.

\begin{abstract}
The Distance Education gained prominence with the advancement of Technologies, which drew the attention of researchers to the topic. Therefore, it justifies the importance of understanding the dynamics of this field of study to the progress of science and identifying gaps and different points of view in knowledge production. This study aimed to analyze the international profile of academic
\end{abstract}

\footnotetext{
${ }^{1}$ Recebido em 02/09/2015; aprovado em 02/07/2017.

${ }^{2}$ Universidade Federal Fluminense - thatapellegrini@gmail.com.

${ }^{3}$ Universidade de São Paulo - sheila_serafim@yahoo.com.br.

${ }^{4}$ Instituto Federal do Rio de Janeiro - Maxwel_ferreira@ hotmail.com.

${ }^{5}$ Universidade Federal Fluminense/PPGA - malvarenga@id.uff.br.
} 
research about Distance Education and, more specifically, Brazilian contribution on the subject. Bibliometric techniques were used in the study since the scientific production's indicators portray the development of an area of knowledge. The research gathered the terms Distance Education, Elearning and Elearning at the database Web of Science (WoS). The following procedures were performed: (1) determining the most appropriate terms for extracting data concerning the interests of research; (2) search and extraction at the databases; (3) cleaning and organizing data, and (4) bibliometric analysis and interpretation. The results showed that the issue is a global concern and presents interaction between some countries, especially the United States, as it is the country that published the most on the subject. A great number of authors, who together are 17.789, indicating that the subject is moving towards maturity regarding international analysis, is researching the Distance Education. The results also showed that papers about Distance Education in Brazil have international cooperation, which may indicate that Brazil is publishing alongside the main countries researching on the topic. From this evidence, the research could contribute to the map of academic research profile on Distance Education in Brazil and in the world that can be useful to researchers.

Keywords: Distance Education; Research Profile; Bibliometric.

\section{RESUMEN}

La Educación a Distancia gano destaque con el avance de las tecnologías, y por eso muchos investigadores se volvieron para el tema. A partir de eso, se justifica la importancia de comprender la dinámica del campo de estudio acerca de la Educación a Distancia para el avance de la ciencia y para la identificación de lagunas y vieses en la producción del conocimiento. Ese estudio tuve como objetivo analizar el perfil internacional de la pesquisa académica sobre Educación a Distancia, y más específicamente, la participación brasileña en esas pesquisas. Fueron utilizadas técnicas bibliométricas, ya que los indicadores de producción científica retratan el desarrollo de una área de conocimiento. El estudio combinó los términos Distance Education, E-learning, Distance Education, E-learning, y Elearning, en la base de datos Web of Science (WoS). Fueron realizados los siguientes procedimientos: (1) definición de los términos más adecuados para la extracción de datos de artículos relativos al interés de la pesquisa; (2) búsqueda y extracción en las bases de datos; (3) limpieza y organización de los datos y (4) análisis bibliometricas e interpretación. Los resultados apuntan que el tema es de interés global y presenta interacción entre algunos países, con destaque para los Estados Unidos, como el país que tiene más publicaciones acerca del tema. La Educación a Distancia esta siendo investigada por various autores, un total de 17.789, indicando que el tema camina para la madurez al respecto del campo de estudios internacional. Los resultados apuntan, aun, que las publicaciones sobre Educación a Distancia en Brasil poseen cooperación internacional, lo que puede ser un indicativo de que el Brasil está publicando con los principales países que investigan sobre el tema. A partir de esta evidencia, la investigación podría contribuir al mapa de perfil investigación académica sobre Educación a Distancia en Brasil y en el mundo que puede ser útil para los investigadores.

Palabras-clave: Educación a Distancia; Perfil de Investigación; Bibliometría.

\section{INTRODUÇÃO}

As Instituições Educacionais de todo o mundo têm sido incentivadas a aprimorar e expandir sua forma de transferir conhecimento diante de novas necessidades criadas pela globalização. Nesse quadro, uma possibilidade encontrada foi a de educar sem, necessariamente, precisar de espaço físico, tornando a Educação a Distância, com apoio de

REAd | Porto Alegre - Vol. 23 - No Especial - Dezembro 2017 - p. 371-393 
tecnologias e mídias, o instrumento de ensino e aprendizagem mais utilizado (CASSUNDÉ; CASSUNDÉ JR, 2012).

Em decorrência, aumentam o estudo e a pesquisa sobre essa modalidade de ensino, respondendo-se a uma demanda mundial. Tal aumento está associado, ainda, ao avanço das Tecnologias da Informação e Comunicação (TICs) e sua capacidade de armazenar, controlar e transmitir informação, tendo em vista a relação custo/benefício e as similaridades na aprendizagem dos alunos quando comparada à educação presencial (FORMIGA, 2003).

No Brasil, a Educação a Distância ganhou destaque na década de 1970, com o acordo realizado entre a Universidade de Brasília $(\mathrm{UnB})$ e a Open University, do Reino Unido. Na ocasião, a UnB passou a ofertar vinte cursos de extensão nessa modalidade, sendo seis deles levados pela Open University, beneficiando pessoas de todos os estados do Brasil (FONTANA et al., 2014).

O progresso da Educação a Distância pode estar associado à criação da primeira Lei sobre as bases e diretrizes em Educação a Distância no Decreto Lei. 4.024/61, que indica a possibilidade da educação por meio da modalidade à distância. Contudo, somente em 2005 a Educação a Distância foi caracterizada pelo poder público como modalidade educacional segundo o Decreto de Lei 5.622/05 (COSTA; COCHIA, 2013).

De acordo com o Relatório Analítico da Aprendizagem a Distância no Brasil (2013), a maioria das instituições (51,5\%), independentemente do tipo de oferta de Educação a Distância, indicam que houve um aumento dos investimentos na modalidade do ano 2012 para 2013 em 35\%, além do crescimento da expectativa da maioria das instituições $(64,6 \%)$ quanto ao aumento de investimentos em Educação a Distância para os próximos anos.

O cenário do mercado de trabalho está se estruturando em novas condições, configurando-se mais informatizado. Dominar amplamente os referenciais pertinentes à atividade que se pretende exercer é um diferenciador para inserir-se no mercado ou nele manter-se. Grandes empecilhos para esse domínio são a agilidade com que as informações circulam e as dificuldades de acesso a cursos em ambiente físico, seja por dificuldade de se coordenarem atividades diversas na vida do indivíduo - fator tempo - ou pelas precárias condições de acesso determinadas pelos sistemas de governo a uma parcela considerável da população brasileira (GATTI, 2008; KENSKI; BRUNSTEIN, 2010). Nesse cenário, a Educação a Distância entra em pauta como recurso mediador de tais dificuldades, seja pela possibilidade de aquisição de conhecimento em diferentes áreas do saber, seja pela flexibilidade de tempo e espaço tidos como os principais benefícios da modalidade.

REAd | Porto Alegre - Vol. 23 - No Especial - Dezembro 2017 - p. 371-393 
Nas décadas de 1960-1970, a Educação a Distância com uso de tecnologias passou a ser vista em sua amplitude e pesquisada como ciência aplicada. Busca-se a comprovação dos conhecimentos de forma cientifica para auxílio na resolução de problemas. $O$ desenvolvimento da tecnologia influenciou o campo de estudos e pesquisa, ampliando a discussão sobre o papel de determinadas mídias como o rádio, os telecursos, os computadores sem rede e até o e-learning (ROMISZOWSKI, 2009).

Diante desse avanço, alguns pesquisadores se voltaram para o estudo de temas relacionados à Educação a Distância. A compreensão do estado do conhecimento nessa área é importante para a evolução da ciência, pois permite identificar possibilidades de integração de ideias e pontos de vista de diferentes autores, além de permitir, também, a identificação de lacunas e vieses na produção do conhecimento (CASSUNDÉ; CASSUNDÉ JR, 2012).

É justificável, portanto, a importância de compreender a dinâmica desse campo de estudo sobre Educação a Distância. Tem-se, neste termo, como questão de pesquisa entender qual a dinâmica da produção acadêmica sobre Educação a Distância no período de 1956 a 2016.

Para isso, o estudo pretende analisar o perfil da pesquisa acadêmica sobre Educação a Distância e, mais especificamente, a participação brasileira em tal produção científica. Entende-se por perfil de pesquisa o método que se baseia na bibliometria, sendo seu escopo ampliado para a análise de palavras por meio da mineração de textos (MOTTA, et al. 2011).

O instrumento para a consecução deste estudo são os indicadores bibliométricos, que permitem a análise da produção do conhecimento científico e fazem avançar o estado da arte em determinado campo da ciência em uma perspectiva nacional e internacional (KOBASHI; SANTOS, 2006; MACIAS-CHAPULA, 1998). Com o uso dos indicadores, buscaram-se dados para leitura do perfil de pesquisas sobre Educação a Distância existentes no Brasil. Na fundamentação teórica, elucida-se o que seria a bibliometria, contrastando-se essa ferramenta com outras que contemporaneamente surgem, ou são refinadas, a partir do que têm oferecido os avanços tecnológicos, além de se demonstrarem os resultados encontrados na busca por pesquisas sobre Educação a Distância.

Os procedimentos metodológicos usados, inclusive a necessária discriminação da base de dados utilizada e a justificativa que a torna pertinente, estão relatados em tópico próprio, ao qual é imediatamente sucedido pelas interpretações e análises do material recolhido. Nas considerações finais, pretende-se a associação entre as ideias aqui expostas, tentando-se conclusões que ajudem a fundamentar e instiguem novas pesquisas sobre o tema.

REAd | Porto Alegre - Vol. 23 - No Especial - Dezembro 2017 - p. 371-393 


\section{O MÉTODO DO PERFIL DE PESQUISA}

O termo bibliometria começou a ser usado nos anos de 1920, como um conjunto de métodos para mensurar textos de qualquer natureza. $\mathrm{O}$ aumento da produtividade científica registrada fez com que a bibliometria também avançasse, com o uso de modelos matemáticos e organização sistêmica das informações obtidas (VANTI, 2002; MORETTI; CAMPANARIO, 2009).

O processo de avalição por meios quantitativos pode ser feito com foco em diversas áreas da Ciência da Informação, subdivididas em: bibliometria, cienciometria, informetria e, mais recentemente, webometria (MACÍAS-CHAPULA, 1998; VANTI, 2002).

As áreas possuem diferenças quanto ao objeto de estudo, as suas variáveis, os métodos e os seus objetivos, conforme podem ser observados no Quadro 1.

Quadro 1 - Comparação das aplicações dos distintos métodos quantitativos

\begin{tabular}{|c|c|c|c|c|}
\hline $\begin{array}{l}\text { Tipologia/ } \\
\text { Subcampo }\end{array}$ & Bibliometria & Cientometria & $\begin{array}{c}\text { Informetria/ } \\
\text { Infometria }\end{array}$ & Webometria \\
\hline Objeto de estudo & $\begin{array}{l}\text { Livros, } \\
\text { documentos, } \\
\text { revistas, artigos, } \\
\text { usuários. }\end{array}$ & $\begin{array}{l}\text { Disciplinas, } \\
\text { assuntos, campos } \\
\text { científicos e } \\
\text { tecnológicos, } \\
\text { patentes, } \\
\text { dissertações e teses. }\end{array}$ & $\begin{array}{l}\text { Palavras, documentos, } \\
\text { banco de dados, } \\
\text { comunicações } \\
\text { informais (inclusive } \\
\text { em âmbito não } \\
\text { científico) e homepage } \\
\text { na www. }\end{array}$ & $\begin{array}{l}\text { Sítios na www, (URL, } \\
\text { título, tipo, domínio, } \\
\text { tamanho e links) motores } \\
\text { de busca. }\end{array}$ \\
\hline Variáveis & $\begin{array}{l}\text { Número de } \\
\text { empréstimos } \\
\text { (circulação) e de } \\
\text { citações, } \\
\text { frequência de } \\
\text { extensão de frases. }\end{array}$ & $\begin{array}{l}\text { Fatores que se } \\
\text { diferenciam as } \\
\text { subdisciplinas. } \\
\text { Como os cientistas } \\
\text { se comunicam. }\end{array}$ & $\begin{array}{l}\text { Medir a recuperação, } \\
\text { relevância e } \\
\text { revocação. }\end{array}$ & $\begin{array}{l}\text { Número de páginas por } \\
\text { eixo, número de linhas por } \\
\text { eixo, número de links que } \\
\text { remetem ao mesmo sítio, } \\
\text { situações, estratégias de } \\
\text { busca. }\end{array}$ \\
\hline Métodos & $\begin{array}{l}\text { Ranking, } \\
\text { Frequência e } \\
\text { distribuição. }\end{array}$ & $\begin{array}{l}\text { Análise de conjunto } \\
\text { de correspondência, } \\
\text { co-ocorrência de } \\
\text { termos, expressões, } \\
\text { palavras-chave. }\end{array}$ & $\begin{array}{l}\text { Modelo vetor espaço, } \\
\text { modelos booleanos de } \\
\text { recuperação, modelos } \\
\text { probabilísticos, } \\
\text { linguagem de } \\
\text { processamento, } \\
\text { abordagem baseada no } \\
\text { conhecimento, } \\
\text { tesauros. }\end{array}$ & $\begin{array}{l}\text { Fator de Impacto da Web } \\
\text { (FIW), densidade dos } \\
\text { links, citações, estratégias } \\
\text { de busca. }\end{array}$ \\
\hline Objetivos & $\begin{array}{l}\text { Alocar recursos, } \\
\text { pessoas, tempo, } \\
\text { dinheiro. }\end{array}$ & $\begin{array}{l}\text { Identificar } \\
\text { domínios de } \\
\text { interesse, } \\
\text { compreender como } \\
\text { e o quanto os } \\
\text { cientistas se } \\
\text { comunicam. }\end{array}$ & $\begin{array}{l}\text { Melhorar a eficiência } \\
\text { da recuperação de } \\
\text { informação, identificar } \\
\text { relações entre os } \\
\text { diversos sistemas de } \\
\text { informações. }\end{array}$ & $\begin{array}{l}\text { Avaliar o sucesso de } \\
\text { determinados sítios, } \\
\text { detectar a presença de } \\
\text { instituições, pesquisadores } \\
\text { na rede e melhora a } \\
\text { eficiência dos motores de } \\
\text { busca na recuperação das } \\
\text { informações. }\end{array}$ \\
\hline
\end{tabular}

Fonte: Vanti (2002).

REAd | Porto Alegre - Vol. 23 - No Especial - Dezembro 2017 - p. 371-393 
Este estudo utilizará, especificamente, a bibliometria, que consiste em três fases: a) inteligência, b) análise e projeto, c) escolha. Na fase da inteligência ocorre identificação do tema da pesquisa, escolha da fonte de informação, refinamento da busca, obtenção dos dados e limpeza dos mesmos. Na fase de análise e projeto, são feitas análises e, por fim, na fase da escolha tem-se a interpretação e utilização das informações coletadas (PORTER; CUNNINGHAM, 2005). Tem-se como objeto de análise: quantos trabalhos já foram publicados sobre o tema, quantos e quais os principais autores escreveram sobre ele e quais os principais países e instituições que publicam sobre Educação a Distância (VANTI, 2002).

\section{ESTUDOS BIBLIOMÉTRICOS SOBRE EDUCAÇÃO A DISTÂNCIA NO BRASIL}

O panorama da área de Educação a Distância no país tem sido estudado com o uso da bibliometria. Mais especificamente, o termo "Educação a Distância" tem sido analisado em diversas bases como a do Encontro da Associação Nacional de Pós-Graduação e Pesquisa em Administração (EnANPAD), SciELO, Coordenação de Aperfeiçoamento de Pessoal de Nível Superior (CAPES) e de dissertações e teses.

Santos et al. (2007) realizaram um estudo sobre a literatura brasileira em Educação a Distância, analisando teses e dissertações publicadas entre 1997 a 2007. Nesse estudo, os termos de busca: Educação a Distância e E-learning foram pesquisados na base científica SciELO no campo "assunto". Em tal estudo, concluiu-se que a expansão da Educação a Distância foi seguida do crescimento de publicações sobre ela, contudo houve demora em se dar destaque ao tema, sendo poucos relatos documentados encontrados e havendo poucas pesquisas científicas com continuidade.

O estudo realizado por Mill e Oliveira (2014) analisou, por meio da bibliometria, teses sobre Educação a Distância. Nesse caso, os autores consideraram o termo "Pesquisa" como o elemento necessário para a construção do conhecimento em determinada área. Posteriormente, a partir de um filtro das que tratavam especificamente de Educação a Distância, ambos os termos foram combinados. Nesse estudo, foram analisadas teses de 2002 a 2012 com os dados da Base de Teses catalogadas pelo Grupo Horizonte da Universidade Federal de São Carlos (UFSCar). O estudo concluiu que a maior quantidade de ocorrências de defesas dos trabalhos concentra-se após 2005 e as pesquisas em Educação a Distância obtiveram a maior quantidade de teses defendidas que a pesquisa, termo chave explicado acima, o que coincide com a sua expansão.

REAd | Porto Alegre - Vol. 23 - No Especial - Dezembro 2017 - p. 371-393 
Cassundé e Cassundé Junior (2012) analisaram o estado da arte sobre Educação a Distância em Administração no período de 1998 a 2011, tendo como termos de busca as seguintes palavras: ead, educação à (a) distância, ensino à (a) distância, e-learning, ambiente virtual de aprendizagem e ensino on-line na base de dados do EnANPAD. A partir da análise de 48 artigos, concluiu-se que a maioria dos artigos é composta por dois, três ou mais autores, sugerindo que possam existir grupos de pesquisa sobre Educação a Distância, contudo não há continuidade das pesquisas.

Em outra análise realizada por Ferreira e Sadoyama (2015), foi considerado o período de 2004 a 2014, sendo o termo de busca Educação a Distância. Adotou-se a base de dados do EnANPAD e a Biblioteca Digital de Teses e Dissertações (BDTD), além de produções no portal de periódicos da Capes, totalizando 60 publicações. Esse estudo concluiu que a Educação a Distância no país está em crescimento, sendo enfatizado a formação docente, a profissionalização e a educação inclusiva.

Houve consenso nos resultados dos estudos analisados indicando um crescimento da área de Educação a Distância em termos de publicação nas principais bases de pesquisa do país considerando uma análise feita a partir do final da década de 80 , quando a oferta e a demanda da Educação a Distância tornaram-se mais recorrentes.

A partir destes estudos, desenvolveu-se um estudo de caráter bibliométrico em tendo em vista a atualização do perfil de pesquisa sobre Educação a Distância no Brasil, tendo como principal diferencial em relação às demais pesquisas apresentadas a base de dados internacional.

\section{PROCEDIMENTOS METODOLÓGICOS}

Propõe-se neste estudo, pesquisa exploratória e descritiva. Uma análise exploratória é aplicada quando a área de pesquisa tem pouco conhecimento acumulado, como foi explicado na seção anterior. A pesquisa descritiva é feita com a finalidade de evidenciar as características e também possibilitar as interações entre os estudos (VERGARA, 2000).

Realizou-se a pesquisa a partir de estudo bibliométrico, cuja finalidade é analisar o campo do conhecimento já descrito, apoiado em artigos científicos e com o auxílio de programas de computador, para que pudessem ser feitas relações entre autores e suas tendências (SPINAK, 1996). As etapas seguidas nesse estudo são apresentadas na Figura 1.

REAd | Porto Alegre - Vol. 23 - No Especial - Dezembro 2017 - p. 371-393 
Figura 1 - Etapas do Método do Perfil de Pesquisa

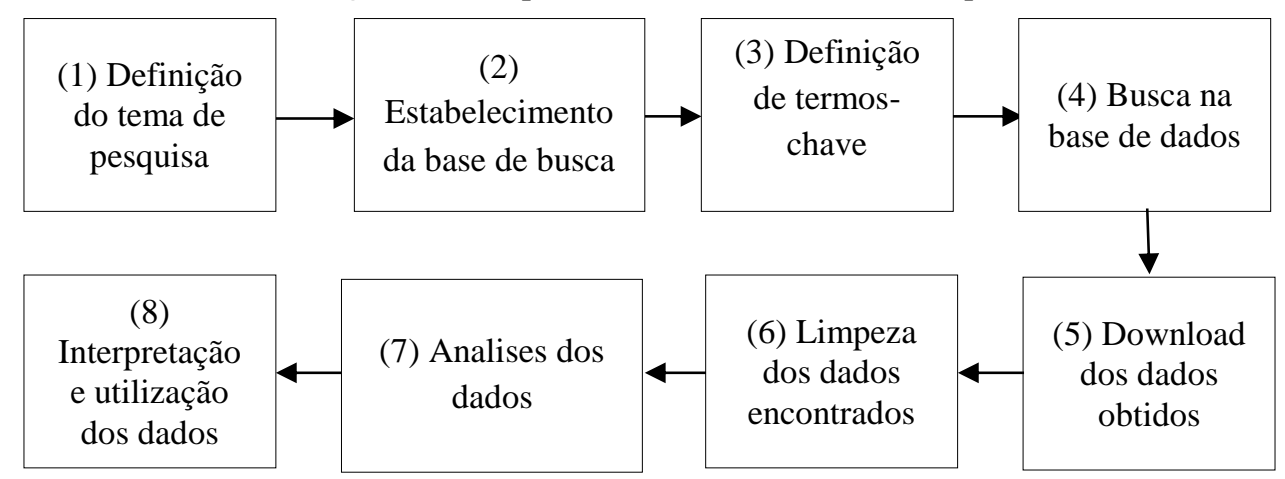

Fonte: elaborado pelo autor com base em Porter e Cunningham (2005), Motta, Garcia e Quintella (2014), Ferreira et al. (2012) e adaptado de Motta e Quintella (2012).

O procedimento descrito na sequência segue os passos apresentados na Figura 1. Para responder ao problema de pesquisa abordado (qual é a dinâmica da produção acadêmica em Educação a Distância no período de 1956 a 2016?), elegeu-se a base de busca Web of Science $(W o S)$ por ser uma das bases internacionais de maior relevância na área de Ciências Sociais Aplicadas e de acesso gratuito nas instituições públicas de educação superior (MOTTA; QUINTELLA, 2012), sendo essa a execução da Etapa 2 descrita na Figura 1. Esta base foi utilizada tanto para a coleta de dados sob a perspectiva mundial quanto para o recorte do Brasil.

Posteriormente, definiu-se a estratégia de busca para que os dados pudessem ser extraídos da base WoS (Etapa 3). O critério utilizado foi por tópico que inclui os campos Título, Resumo e Palavras-chave. Em seguida, para a definição dos termos de busca, foram consultados autores que pesquisam sobre o tema, como por exemplo, Santos et al. (2007) e, assim, os termos-chave escolhidos consistem em "Distance Education" OR "E-Learning” OR "Elearning”. O operador boleano "OR" foi utilizado para combinar as palavras e para que não houvesse resultados repetidos na busca. Foi realizado um refinamento nos resultados em relação ao tipo de documento, sendo incluídos apenas “Article". Os termos foram usados entre aspas (") para que evitar que artigo que contivesse apenas um termo fosse incluído, como seria no caso de "distance" ou "education", devendo ser considerado na busca o termo completo, ou seja, "distance education".

Os dados foram coletados em 24 de setembro de 2016, sendo esta a execução das Etapas 4 e 5 da Figura 1. Cabe destacar que toda vez que aqui houver citação à produção científica sobre Educação a Distância, tal produção refere-se à extração nessa base de dados e nessa data. A demarcação é importante, pois há uma quantidade representativa da produção científica sobre o tema publicada na base a partir de setembro de 2016 e que não foi atingida REAd | Porto Alegre - Vol. 23 - No Especial - Dezembro 2017 - p. 371-393 
devido aos critérios utilizados. Assim, cabe reforçar que os dados referentes ao ano de 2016 correspondem aos artigos disponíveis na base até a data em que a busca foi realizada.

Depois da obtenção dos dados, procedeu-se limpeza dos mesmos com a ajuda do software VantagePoint $\AA$, onde foram padronizados os nomes dos autores, das instituições e países para que pudessem ser analisados (Etapa 6). Sequencialmente, para que se analisassem as publicações brasileiras separadamente, efetuou-se recorte nos dados.

$\mathrm{Na}$ próxima etapa, foram realizadas análises (Etapa 7) para descrever o cenário do campo de pesquisa por meio: (1) quantidade de artigos publicados; (2) autoria dos artigos publicados; (3) instituições de afiliação dos autores; (4) periódicos e eventos que mais publicam sobre o tema; (5) rede de colaboração científica entre países e (6) os temas de interesse dos três autores que mais publicam no mundo. Foram apresentados nesse estudo, em geral, o ranking dos 12 autores, países e instituições mais representativos. Essa padronização dos doze (12) mais representativos foi necessária única e exclusivamente por limitação de espaço nesse documento.

Em relação ao que ocorre no Brasil, foram feitas analises baseadas em: (1) quantidade de artigos publicados; (2) autoria dos artigos publicados; (3) rede de colaboração científica entre o Brasil e os demais países e (4) os temas mais pesquisados pelos cinco autores que mais publicam sobre o assunto que sobre aqui se discorre. As análises estão apresentadas na seção seguinte e, em paralelo, a interpretação dos dados (Etapa 8).

\section{APRESENTAÇÃo E ANÁLISE DOS DADOS NO MUNDO}

A partir da organização dos dados, conforme descrito no tópico anterior, obtiveram-se os resultados descritos a seguir.

Foram encontrados, na $W o S, 7.068$ artigos publicados, referentes ao termo de busca, no período de 1956 (ano da primeira publicação) até o ano de 2016. É importante destacar que os resultados referentes ao ano de 2016 não foram excluídos da análise, mas dizem respeito até a data de busca em que os dados foram coletados e, possivelmente, outros artigos seriam publicados no decorrer do ano de 2016.

Com os resultados, pôde-se notar que as publicações sobre o tema Educação a Distância, têm aumentado ao longo do período analisado. A evolução pode ser dividida em três períodos, de 1956 a 1990 como o surgimento das publicações sobre Educação a Distância, de 1991 a 2007 como um aumento progressivo na quantidade e de 2008 a 2016,

REAd | Porto Alegre - Vol. 23 - No Especial - Dezembro 2017 - p. 371-393 
período em que as publicações sobre Educação a Distância foram intensas, tendo por ápice o ano de 2012. A distribuição das publicações ao longo do tempo pode ser observada na Figura 2.

Figura 2 - Evolução da publicação de artigos com tema Educação a Distância até 2015

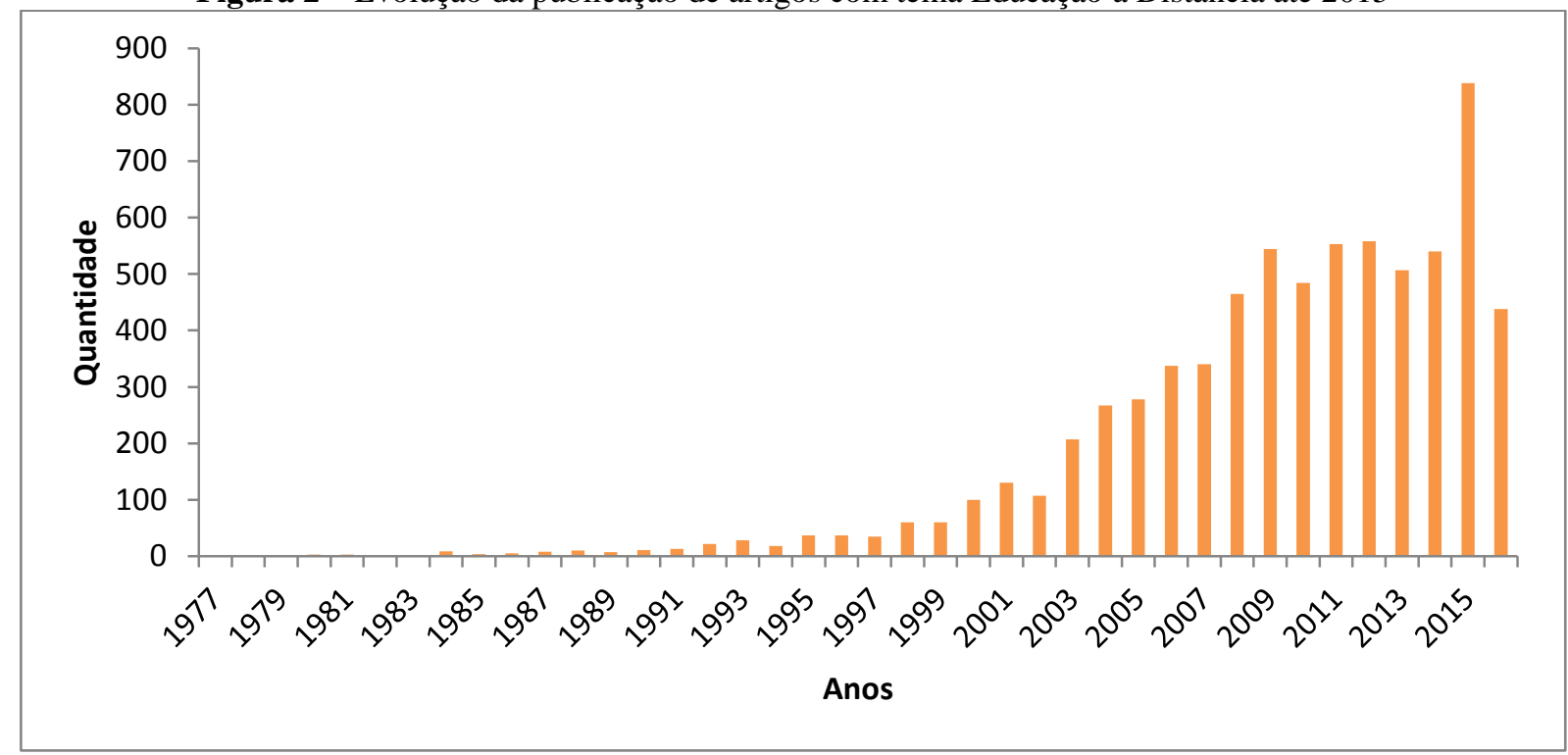

Fonte: elaborado pelo autor com base nos dados da pesquisa, por meio do VantagePoint v.8.

Pôde-se quantificar menos de 12 publicações por ano na primeira fase, de 13 a 340 publicações por ano na segunda fase e de 438 a 558 publicações por ano na terceira fase. $\mathrm{O}$ aumento no número de publicações na primeira fase (1956-1990) pode estar associado ao surgimento das redes, a Internet e do protocolo TCP/IP. A segunda fase pode estar associada à expansão da Word Wide Web, surgimento de diversos sites de busca e a criação do HTTPS, que permite a troca de dados criptografados pela Web. A terceira fase pode estar associada ao surgimento da Web 2.0, a consolidação da Internet e evolução das tecnologias. Esses acontecimentos podem ter contribuído para avanços na modalidade de Educação a Distância (RIBEIRO; MENDONÇA; MENDONÇA, 2007).

Na Figura 3, o indicador não cumulativo (faixa azul) indica a quantidade de novos artigos, ano a ano, enquanto o indicador cumulativo (faixa vermelha) indica a quantidade de novos artigos ano a ano acumulada com os anos anteriores. Pode-se observar na Figura 3 que houve crescimento acumulado na quantidade de artigos publicados no decorrer do tempo, sendo tal crescimento mais representativo a partir da década de 1990. Isso pode representar um aumento no interesse de pesquisadores pelo tema. 
Figura 3 - Evolução da quantidade de publicações sobre o tema Educação a Distância

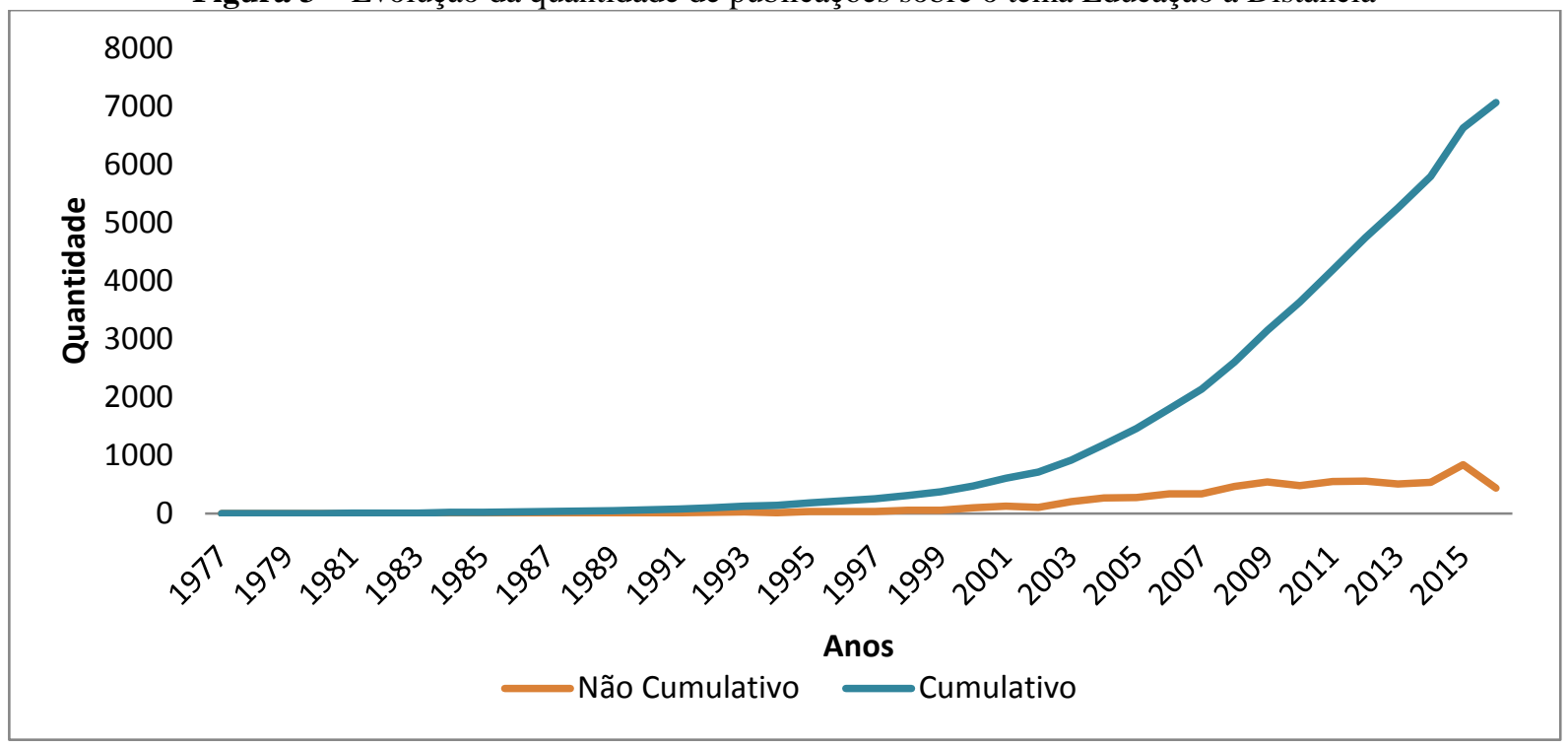

Fonte: elaborado pelo autor com base nos dados da pesquisa, por meio do VantagePoint v.8

Com relação aos autores que publicaram sobre o tema em questão, foram encontrados 17.789. Desses autores, os 12 com a maior quantidade de publicações foram apresentados na Tabela 1. Os autores com menos de 10 publicações não foram apresentados por limitação de espaço neste documento. Tal resultado pode indicar o interesse dos autores em publicar sobre o tema Educação a Distância.

Tabela 1 - Autores que mais publicaram sobre o tema Educação a Distância

\begin{tabular}{ccc}
\hline Ordem & Quantidade de Publicações & Autores \\
\hline 1 & 26 & Richardson, John Thomas Edwin \\
2 & 17 & Koper, Rob \\
3 & 15 & Fernandez-Manjon, Baltasar \\
4 & 14 & Chen, Chih-Ming \\
5 & 14 & Chen, Nian-Shing \\
6 & 14 & Kinshuk \\
7 & 13 & De Marcos, Luis \\
8 & 13 & Huang, Yueh-Min \\
9 & 13 & Tsai, Chia-Wen \\
10 & 12 & Gaeta, Matteo \\
11 & 12 & Garcia-Penalvo, Francisco-Jose \\
12 & 11 & Virvou, Maria \\
\hline Fonte: elaborado pelo autor com base nos dados da pesquisa, por meio do VantagePoint v.8.
\end{tabular}

Podem-se observar na Tabela 2, os 12 periódicos e/ou eventos que mais publicaram sobre Educação a Distância, tendo como destaque o periódico Computers \& Education com 424 publicações, o que representa 6,39\% das publicações encontradas. Os demais periódicos e/ou eventos sobre o tema não foram apresentados por limitação de espaço neste documento.

REAd | Porto Alegre - Vol. 23 - No Especial - Dezembro 2017 - p. 371-393 
Tabela 2 - Periódicos/Eventos que mais publicaram sobre o tema Educação a Distância

\begin{tabular}{ccc}
\hline Ordem & Quantidade de Publicações & Periódico/Evento \\
\hline 1 & 424 & Computers \& Education \\
2 & 215 & Educational Technology \& Society \\
3 & 189 & International Review of Research in Open and Distance Learning \\
4 & 169 & British Journal of Educational Technology \\
5 & 131 & Computers in Human Behavior \\
6 & 101 & Distance Education \\
7 & 97 & International Journal of Engineering Education \\
8 & 82 & Expert Systems with Applications \\
9 & 80 & Journal of Universal Computer Science \\
10 & 69 & Journal of Computer Assisted Learning \\
11 & 66 & Nurse Education Today \\
12 & 65 & BMC Medical Education \\
\hline
\end{tabular}

Fonte: elaborado pelo autor com base nos dados da pesquisa, por meio do VantagePoint v.8.

As instituições de afiliação dos autores que mais tiveram publicações associadas ao tema estão listadas na Tabela 3. São instituições com 39 até 131 publicações e são representadas pelos seguintes países: Reino Unido, Estados Unidos (EUA), Canadá, Taiwan, Austrália e Brasil. Destacam-se a Open University (Reino Unido), com 131 publicações, e a Universidade da Flórida (EUA), com 68 publicações. Foram escolhidas apenas as 12 Instituições com o maior número de publicações em virtude da limitação de espaço neste documento. As demais Instituições possuem menos de 39 publicações.

Destaca-se a Universidade de São Paulo que está entre as dez universidades do mundo que mais publicam sobre o tema, com 41 publicações, como pode-se observar na Tabela 3.

Tabela 3 - Instituições que mais publicam sobre o tema

\begin{tabular}{cccc}
\hline Ordem & Quantidade de Publicações & Instituições & Países das Instituições \\
\hline 1 & 131 & Open University & Reino Unido \\
2 & 68 & University of Florida & EUA \\
3 & 62 & Athabasca University & Canadá \\
4 & 62 & National Cheng Kung University & Austrália \\
5 & 46 & University of Sydney & Austrália \\
6 & 43 & Monash University & Taiwan \\
7 & 43 & National Chiao Tung University & EUA \\
8 & 43 & Texas A\&M Univ & EUA \\
9 & 42 & University of North Carolina & Brasil \\
10 & 41 & University of Sao Paulo & Taiwan \\
11 & 40 & National Taiwan University of Science and & Canadá \\
\hline
\end{tabular}

Fonte: elaborado pelo autor com base nos dados da pesquisa, por meio do VantagePoint v.8

REAd | Porto Alegre - Vol. 23 - No Especial - Dezembro 2017 - p. 371-393 
A Figura 4 apresenta a representatividade de cada país em termos de publicação sobre Educação a Distância. Os Estados Unidos destacam-se com 17,22\% das publicações, seguido do Reino Unido com 9,02\%, Espanha com 7,83\%, Taiwan com 6,34\% e Canadá com 4,57\%. O Brasil aparece com $1,92 \%$ e os países que estão representados como outros, pois apresentaram a porcentagem das publicações menores que um.

Figura 4 - Participação dos países que publicam sobre o tema Educação a Distância

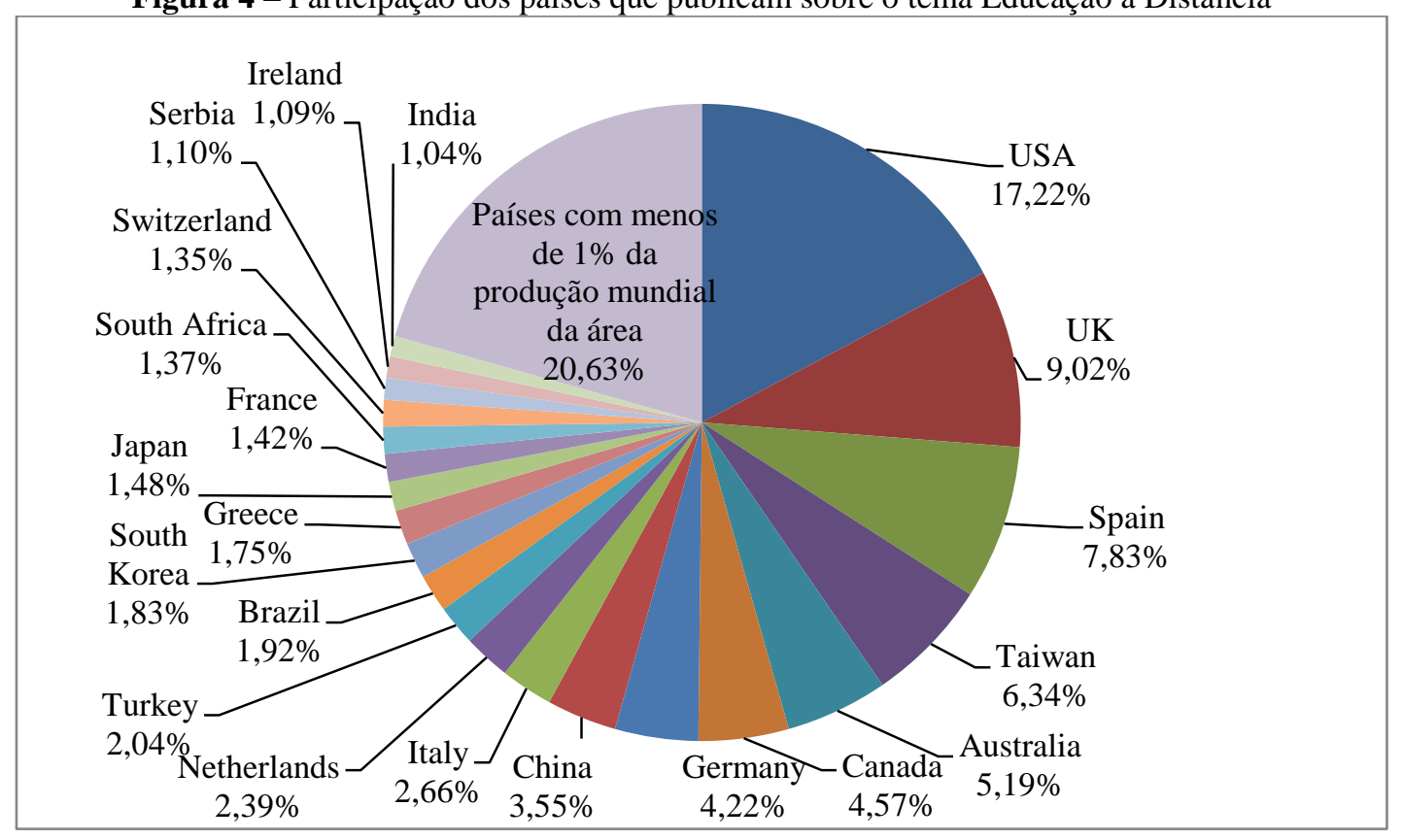

Fonte: elaborado pelo autor com base nos dados da pesquisa, por meio do VantagePoint v.8

A Figura 5 apresenta um mapa da publicação dos países. Os países com tons mais "vermelho" são aqueles que mais publicaram, enquanto os países com tons mais "amarelo" e "laranja" publicaram menos e os na cor "cinza" não foram encontradas publicações.

A partir do cruzamento das publicações entre os países, foi possível identificar redes de colaboração internacional, ou seja, países que publicaram em conjunto, conforme apresentado na Figura 6. As intensidades das linhas representam a quantidade de publicações conjuntas, os nós (países) ligados por ela.

As redes entre países apresentadas na Figura 6 reafirma a notoriedade dos Estados Unidos, que por sua vez, publicam em parceria com países como Reino Unido, Taiwan (China), Canadá, Espanha e Austrália. Esses países foram destacados na figura com um quadrado na cor vermelha. Também podem ser observados os demais países que publicam entre si, destacados na cor azul. 
Figura 5 - Mapa de publicação dos países

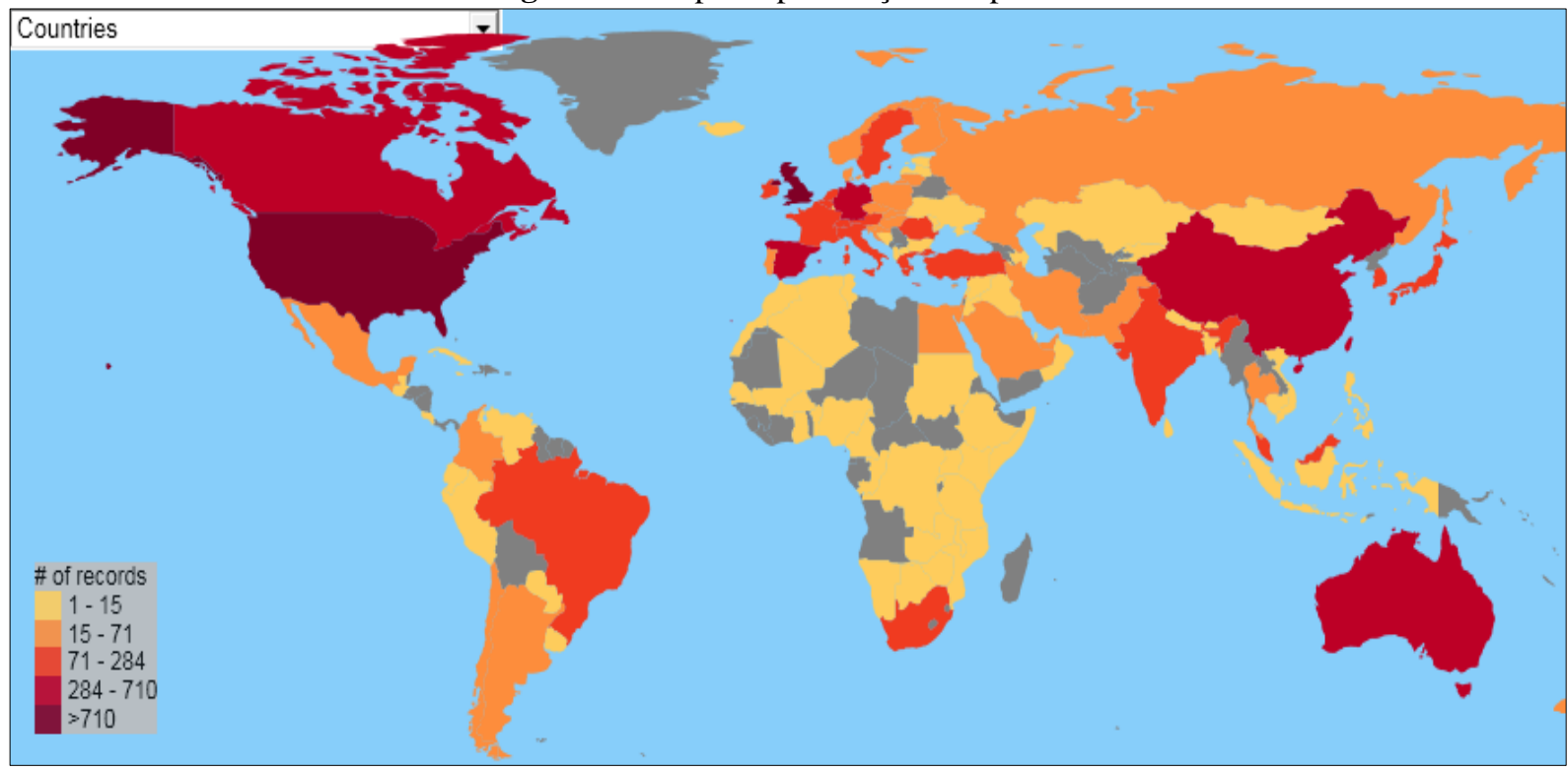

Fonte: elaborado pelo autor com base nos dados da pesquisa, por meio do VantagePoint v.8

Figura 6 - Rede de Colaboração entre países que publicam sobre Educação a Distância

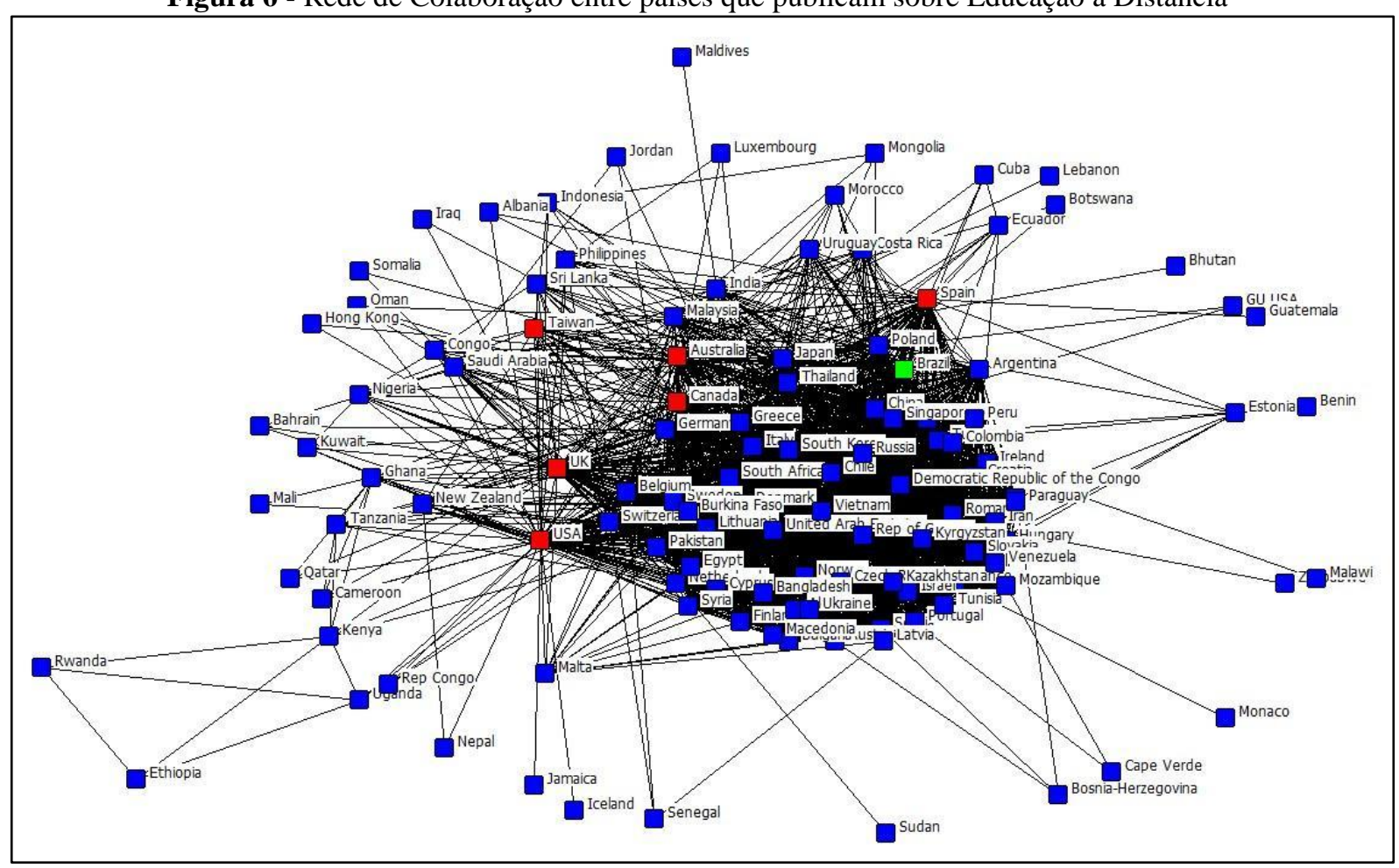

Fonte: elaborado pelo autor com base nos dados da pesquisa, no Software UCINET V6.

Os artigos dos autores que mais publicam em Educação a Distância no mundo contemplam diversos aspectos. Fez-se uma análise do conteúdo de 45 publicações dos autores que mais publicam sobre o tema (Tabela 1). A partir dessa análise, foi possível observar os temas mais abordados nos estudos. 
Pôde-se notar que uma parcela considerável das pesquisas compara os estilos de aprendizagem entre participantes de cursos online e presencial. A temática avaliação de benefícios de uso do e-learning na opinião de estudantes, também foi abordada nas pesquisas. Diversos estudos abordam o desenvolvimento de tecnologias e de materiais midiáticos e suas aplicações em cursos online. Além disso, o tema aprendizagem tem sido associado a recursos online na literatura analisada. E de forma recorrente, a evasão na Educação a Distância, o papel e impactos dos tutores no aprendizado e a análise de desempenho dos estudantes que estudam na modalidade à distância.

Cabe destacar que esses resultados são limitados aos dados coletados na base WoS, no período indicado e que, portanto, não podem ser generalizados. Apresentados os dados mundiais, na sequência, fez-se um recorte com os dados considerando as publicações brasileiras.

\section{APRESENTAÇÃO E ANÁLISE DOS DADOS NO BRASIL}

Fez-se um recorte nos dados brasileiros, analisando o universo de 160 publicações dentro da análise do mundo como descrito. Os autores brasileiros começam a publicar seus trabalhos sobre o tema Educação a Distância no ano de 1998. Como apresenta a Figura 7, o número de publicações é positivo até no ano de 2011 e nos anos 2012, 2013 e 2014 pode-se observar uma relativa queda. Todavia, a quantidade de publicações torna a crescer com destaque importante no ano de 2015.

O início de publicações no Brasil em 1998 pode estar associado ao incentivo dado pelo poder público quanto ao desenvolvimento e veiculação de programas de Educação a Distância em todos os níveis e modalidades de ensino e educação continuada na Lei $n^{\circ}$ 9.394/96. O crescimento a partir do ano de 2005 pode estar associado ao Decreto de Lei 5.622/05, momento em que o poder público caracteriza a Educação a Distância como modalidade educacional. Esses fatores podem ter contribuído para os avanços das pesquisas nas instituições de educação.

REAd | Porto Alegre - Vol. 23 - No Especial - Dezembro 2017 - p. 371-393 
Figura 7 - Evolução da publicação de artigos com tema Educação a Distância até 2016

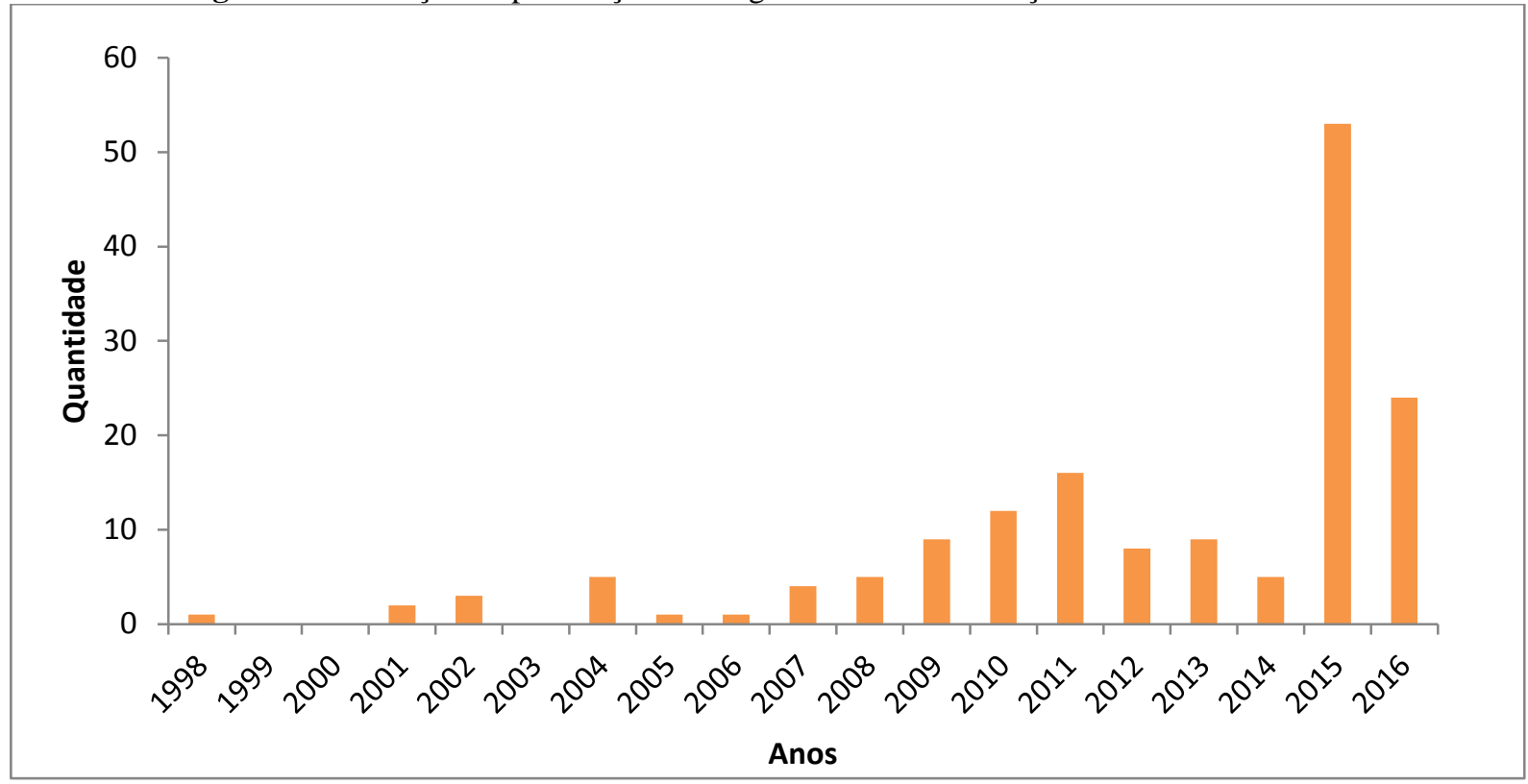

Fonte: elaborado pelo autor com base nos dados da pesquisa, por meio do VantagePoint v.8.

É importante destacar que o tema sugere um crescimento na quantidade de publicações, como apresentado na Figura 8. O indicador não cumulativo indica a quantidade de novas publicações a cada ano e o indicador cumulativo indica a quantidade de novas publicações por ano acumulada com os anos anteriores.

Figura 8 - Evolução dos autores que produziram artigos relacionados ao tema Educação a Distância

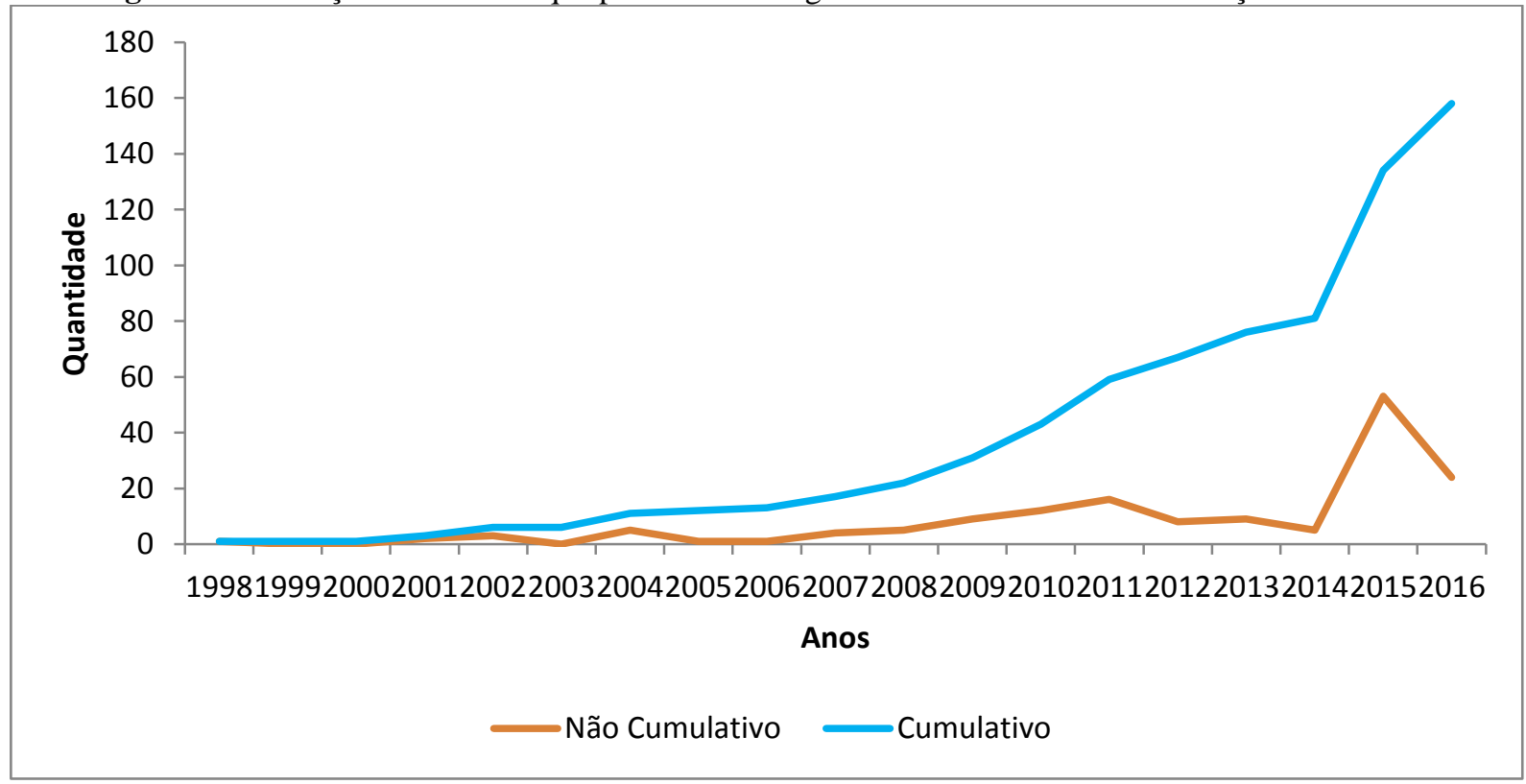

Fonte: elaborado pelo autor com base nos dados da pesquisa, por meio do VantagePoint v.8

REAd | Porto Alegre - Vol. 23 - No Especial - Dezembro 2017 - p. 371-393 
A partir do cruzamento das publicações entre Brasil e demais países, foi possível identificar que o Brasil (representado na Figura 9 pelo quadrado vermelho) publicou em maior volume com países como: Portugal, Estados Unidos, Suíça, Espanha e Canadá, que estão representados na cor azul. Pode-se fazer essa análise, pois a quantidade de trabalhos é expressa pela intensidade das linhas e os países são representados por nós.

Figura 8 - Rede de colaboração entre o Brasil e os demais países que publicam sobre o tema

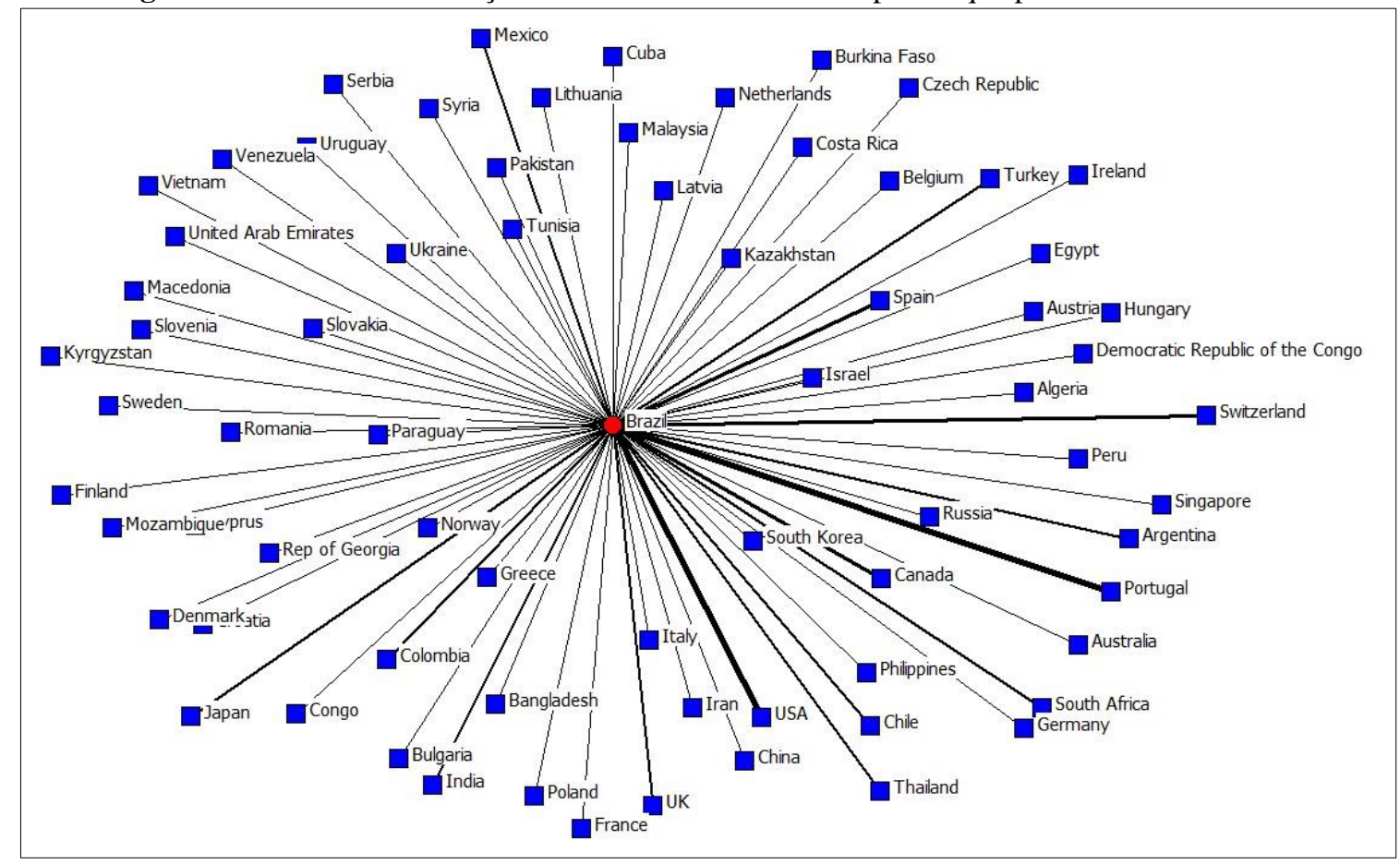

Fonte: elaborado pelo autor com base nos dados da pesquisa, por meio do UCINET V.6.

Com relação às publicações ocorridas no Brasil sobre o tema em questão, estão em destaque na Tabela 4 os cinco autores que mais publicaram sobre Educação a Distância, somando 27 publicações.

Tabela 4 - Ranking dos autores brasileiros que publicam em Educação a Distância

\begin{tabular}{|c|c|c|c|}
\hline Ranking & Quantidade & Brasileiros com mais de 2 publicações & Vínculos \\
\hline 1 & 6 & Wen, Chao Lung & Universidade de São Paulo \\
\hline 2 & 4 & Ciqueto Peres, Heloisa Helena & Universidade de São Paulo \\
\hline 3 & 4 & de Godoy, Simone & Universidade de São Paulo \\
\hline 4 & 4 & Haddad, Ana Estela & Universidade de São Paulo \\
\hline 5 & 3 & Berretin-Felix, Giedre & Universidade de São Paulo \\
\hline 6 & 3 & Costa Mendes, Isabel Amelia & Universidade de São Paulo \\
\hline 7 & 3 & de Lima Tercariol, Adriana Aparecida & UNINOVE-SP \\
\hline
\end{tabular}

REAd | Porto Alegre - Vol. 23 - No Especial - Dezembro 2017 - p. 371-393 
Os artigos dos autores que mais publicam na área abordam diversos aspectos. Os resumos dos trabalhos desses autores foram analisados. Pode-se observar que uma parcela considerável dos estudos trata da análise, concepção, desenvolvimento, implementação e avaliação de cursos online e plataformas e ambientes virtuais de aprendizagem. Essa foi a temática mais abordada nos estudos analisados. Muitos estudos abordam o desenvolvimento de recursos midiáticos complementares e sua avaliação em plataformas online, tais como chat, vídeo conferências dentre outros.

Foi possível observar que o tema "recursos interativos" tem sido muito estudado por esses autores. Como destaque os modelos animados e recursos 3D. Com menor presença também foram encontradas análises de experiências com jogos educativos e simulações. Diversos estudos tratam da avaliação de material didático implementados em cursos online. Também foram encontrados estudos comparativos entre participantes de cursos online e presencial, relatos de experiências de tutores e avaliação de benefícios de uso do $e$-learning na opinião de estudantes.

Em sua maioria, são estudos exploratórios e descritivos, que tratam de um caso específico. A principal abordagem dos estudos analisados é qualitativa. As pesquisas analisadas dizem respeito ao ensino superior ou educação continuada, não sendo encontradas pesquisas em outros níveis de educação.

Saliente-se que: a) as análises acima se referem a publicações dos autores que mais publicam sobre o tema (Tabela 4); b) que esses estudos dizem respeito à base WoS, na data informada nos procedimentos metodológicos.

Apresenta-se ainda, na Tabela 5, as principais universidades brasileiras que mais publicaram sobre o tema.

Observa-se que as universidades são, em sua maioria, universidades públicas federais e estaduais, com exceção da Pontifícia Universidade Católica do Rio de Janeiro (PUC-RJ) que é uma instituição particular.

REAd | Porto Alegre - Vol. 23 - No Especial - Dezembro 2017 - p. 371-393 
Tabela 5 - Universidades brasileiras com maior número de publicações

\begin{tabular}{ccl}
\hline Ranking & Quantidade & \multicolumn{1}{c}{ Universidades com mais de 3 publicações } \\
\hline 1 & 41 & Universidade de São Paulo \\
2 & 11 & Universidade Federal do Rio Grande do Sul \\
3 & 11 & Universidade Federal de Santa Catarina \\
4 & 7 & Universidade Estadual Campinas \\
5 & 7 & Universidade Federal Rio de Janeiro \\
6 & 6 & Universidade Federal Fluminense \\
7 & 6 & Universidade Federal São Paulo (UNIFESP) \\
8 & 6 & Universidade Federal Uberlândia \\
9 & 4 & Pontifícia Universidade Católica do Rio de Janeiro \\
10 & 4 & Universidade Federal de Alagoas \\
11 & 4 & Universidade Federal de Minas Gerais \\
12 & 4 & Universidade Federal do Paraná \\
\hline
\end{tabular}

\section{CONSIDERAÇÕES FINAIS}

A partir dos dados apresentados e discutidos, foi possível analisar o perfil da pesquisa acadêmica sobre a Educação a Distância e, mais especificamente, a participação brasileira nessa produção científica. Os resultados apontaram os principais autores, países, instituições e periódicos que publicaram sobre o tema.

O tema Educação a Distância é de interesse global e apresenta intensa interação entre alguns países, com destaque para os Estados Unidos como o país que mais publicou. O Brasil possui uma representação muito inferior quando comparada à quantidade de publicação dos Estados Unidos.

O tema está sendo pesquisado por uma quantidade representativa de autores, sendo o autor com maior número de publicações Richardson, J. T. E., vinculado à Instituição de maior destaque, a University Open, do Reino Unido. Segundo a análise dos resumos dos autores que mais publicam sobre Educação a Distância, o tema de maior interesse é a avaliação da aprendizagem e o desempenho dos alunos.

As publicações encontradas sobre o tema no cenário mundial tiveram início em 1956 e, no Brasil, somente em 1998, momento em que a quantidade de publicações no mundo eram menos representativas, porém crescente. Isso pode ser explicado pela expansão da Word Wide Web no país e no mundo e pela ampliação do acesso à Internet. Esses fatos podem ter influenciado o interesse de pesquisadores para a produção e, consequentemente, a publicação de pesquisas sobre Educação a Distância.

Considerando as análises no Brasil, há destaque para poucos autores de referência no REAd | Porto Alegre - Vol. 23 - No Especial - Dezembro 2017 - p. 371-393 
tema. Observou-se que houve aumento do número de autores que publicam sobre Educação a Distância, tanto na análise do cenário mundial quanto no Brasil.

Os periódicos que mais publicaram sobre o tema têm como destaque o Computers \& Education, que apresentou o maior número de publicações. $\mathrm{Na}$ análise dos resumos dos autores que mais publicam sobre o tema no Brasil, pôde-se identificar que os assuntos de maior interesse são os que descrevem o desenvolvimento e a avaliação de cursos online.

Os resultados deste estudo corroboram com os achados de Santos et al. (2007), quanto ao aumento da quantidade de publicações sobre o Educação a Distância e quanto a delonga no desenvolvimento da área. Os resultados obtidos também concordam com Mill e Oliveira (2014), cujo maior número de publicações de teses e dissertações encontra-se após 2005. Sobre o estudo realizado por Ferreira e Sadoyama (2015), pode ser confrontado, pois não foram evidenciados os temas de pesquisa com foco em formação de professores e educação inclusiva, cabendo destacar aqui que as bases analisadas e tipos de documentos são diferentes e em períodos diferentes.

Este estudo apresenta como principal contribuição o mapa do campo de publicações sobre Educação a Distância no mundo e com recorte no Brasil, sendo possível identificar o estado da arte sobre o tema e, como principal diferencial, o mapa da rede de colaboração entre os países que publicam sobre o tema. Esses resultados são importantes para entender o campo de estudos na área para que os pesquisadores do tema possam construir uma base mais sólida na revisão de literatura de seus estudos.

Como reiteradamente já dito, usaram-se neste estudo artigos científicos da base de dados Web of Science $(W o S)$, devido à relevância nas ciências sociais aplicadas (MOTTA; QUINTELLA, 2012), o que é um diferencial em relação a outros estudos já realizados. Notese, também, que o fator estudado é, além do perfil acadêmico sobre Educação a Distância no mundo, a participação brasileira nesse contexto.

O que delimita as conclusões deste estudo é o fato de a extração de dados ter ocorrido em base única, Web of Science, acarretando: não acesso à totalidade dos registros sobre o tema e restrição da busca a documentos em língua inglesa. Os resultados conseguidos, portanto, têm que ser considerados segundo essas restrições, de fonte e de idioma, não podendo ser generalizados. Tendo-se ainda, como limitação, os dados do ano de 2016, que dizem respeito aos disponíveis na base $W o S$ até a data indicada.

Como sugestão para novos estudos indica-se a replicação deste estudo considerando novas bases de dados, e outros estudos com a mesma metodologia focada em um país 
específico, como por exemplo, EUA, por ter indicativos de ser referência em publicações no tema. Além disso, outros aspectos podem ser analisados, como a relação de co-autoria, uso de outras técnicas de análise de relações e agrupamentos e outras estratégias de busca como uso dos termos-chave pesquisados entre aspas para restringir a mesma. E, ainda, outros refinamentos podem ser realizados por áreas de conhecimento, como exemplo, à área de ciências sociais aplicadas. Sugere-se que a temática avaliação da aprendizagem e desempenho do estudante em cursos online seja explorada em estudos futuros, uma vez que foram recorrentes nos textos encontrados.

\section{REFERÊNCIAS}

Associação Brasileira de Educação a Distância (ABED). Relatório Analítico da

Aprendizagem a Distância no Brasil - Censo EaD.br (2013). São Paulo: Editora Afiliada, 2014. Disponível em: < http://www.abed.org.br>. Acesso em: 25 jun. 2015.

CASSUNDÉ, F. R.; JUNIOR, N. C. O Estado do Conhecimento Sobre Educação a Distância (EAD) em Administração: por onde caminham os artigos? Gestão e Planejamento, Salvador, v. 13, n. 2, p. 366-374, 2012.

CHAPULA, C. A. M. O Papel da Infometria e da Cienciometria e sua Perspectiva Nacional e Internacional. Ciência da Informação. Brasília, v. 27, n. 2, p. 134-140, 1998.

COSTA, C. J.; COCHIA, C. B. R. A Expansão do Ensino Superior no Brasil e a Educação a Distância: instituições públicas e privadas. Revista Teoria e Prática da Educação, Maringá - PR, v. 16, n. 1, p. 21-32, 2013.

FERREIRA, J. B.; SADOYAMA, A. S. P. Educação a Distância uma Alternativa Para a Educação Profissionalizante, Inclusiva e Continuada: um estudo bibliométrico. Enciclopédia Biosfera, Goiânia, v.11, n.20, p. 348, 2015.

FERREIRA, M. A.; MOTTA, G. S.; QUINTELLA, R.G. O Uso de Indicadores

Cientométricos e Patentométricos na Avaliação de Tecnologias Emergentes por Fundos de Capital Semente. In: CASI - Congresso de Administração, Sociedade e Inovação, Volta Redonda, 2012, Anais.... Volta Redonda: UFF, 2012.

FONTANA, R. L. M., et al. A Trajetória da Educação a Distância. Ciências Humanas e Sociais (Unit), Aracaju, v. 2, n.2, p. 243-255, 2014.

FORMIGA, M. Educação a Distância no Brasil: o que está acontecendo nas empresas e escolas. Revista Brasileira de Aprendizagem Aberta e a Distância, São Paulo, v. 2, n. 2, 
2003.

GATTI, B. Análise das Políticas Públicas para a Formação Continuada no Brasil na Última Década. Revista Brasileira de Educação, Rio de Janeiro, v. 13, n. 37, p. 57-70, 2008.

KENSKI J. M.; Brunstein J. Limites e Possibilidades do E-Learning no Desenvolvimento de Competências Gerenciais. Revista Eletrônica de Administração, Porto Alegre, v. 16, n. 3, p. 685-715, 2010.

MILL, D.; OLIVEIRA, M. R. G. A Educação a Distância em Pesquisas Acadêmicas: uma análise bibliométrica em teses do campo educacional. Educar em Revista, Curitiba, Edição Especial n. 4, p. 15-36, 2014.

MORETTI, S. L. A.; CAMPANARIO, M. A. A Produção Intelectual Brasileira em Responsabilidade Social Empresarial: RSE sob a ótica da bibliometria. RAC, Curitiba, v. 13, Edição Especial, art. 5, p. 68-86, 2009.

MOTTA, G. S. et al. O Perfil da Pesquisa Acadêmica sobre Jogos de Empresas entre 2001 e 2010. In: ENANPAD, 35, Rio de Janeiro 4 a 7 de setembro de 2011. Anais... XXXV ENANPAD, 2011.

MOTTA, G. S.; QUINTELLA, R. H. Assessment of non-financial criteria in the selection of investment projects for seed capital funding: The contribution of scientometrics and patentometrics. Journal of Technology Management \& Innovation, v. 7, n. 3, p. 172-197, 2012.

PORTER, A. L.; CUNNINGHAM, S. W. Tech Mining: exploiting new technologies for competitive advantage. Hoboken, NJ: Wiley, 2005.

RIBEIRO, E. N.; MENDONÇA, G. A. A.; MENDONÇA, A. F. A importância dos Ambientes Virtuais de Aprendizagem na busca de novos domínios na EAD. In: $13^{\circ}$ Congresso Internacional de Educação a Distância. Anais... Curitiba, Brasil. 2007. ROMISZOWSKI, A. J. Aspectos da Pesquisa em EAD. In: LITTO, F. e FORMIGA, M. (Org.). Educação a Distância: O estado da Arte. São Paulo: Person Prentice Hall, 2009. SANTOS, E. M. et al. Educação a distância no Brasil: evolução da produção científica. In: CONGRESSO INTERNACIONAL ABED DE EDUCAÇÃO A DISTÂNCIA, 2007. Anais... $13^{\circ}$ CIAED, 2007.

SANTOS, R. N. M.; KOBASHI, N. Y. Bibliometria, Cientometria, Infometria: conceitos e aplicações. Pesquisa Brasileira em Ciência da Informação e Biblioteconomia, Brasília, v.2, n.1, p.155-172, 2009.

SPINAK, E. Dicionário Enciclopédico de Bibliometría, Cienciometría e Informetría.

REAd | Porto Alegre - Vol. 23 - No Especial - Dezembro 2017 - p. 371-393 
Caracas: UNESCO, 1996.

VANTI, N. A. P. Da Bibliometria à Webometria: uma exploração conceitual dos mecanismos utilizados para medir o registro da informação e a difusão do conhecimento. Ciência da Informação, Brasília, v. 31, n. 2, p. 152-162, 2002.

VERGARA, S. C. Projetos e relatórios de pesquisa em administração. São Paulo: Atlas, 2000.

REAd | Porto Alegre - Vol. 23 - No Especial - Dezembro 2017 - p. 371-393 